Check for updates

Cite this: Chem. Sci., 2020, 11, 845

๑ All publication charges for this article have been paid for by the Royal Society of Chemistry

Received 16th September 2019 Accepted 22nd November 2019

DOI: $10.1039 / c 9 s c 04663 a$

rsc.li/chemical-science

\title{
Remarkably efficient removal of toxic bromate from drinking water with a porphyrin-viologen covalent organic framework $\uparrow$
}

\author{
Tina Skorjanc, (D) a Dinesh Shetty, (D) ab Felipe Gándara, (D) C Liaqat Ali, ${ }^{d}$ Jesus Raya, \\ Gobinda Das, ${ }^{a}$ Mark A. Olson (iD ${ }^{f}$ and Ali Trabolsi (D) *a
}

\begin{abstract}
The presence of carcinogenic bromate $\left(\mathrm{BrO}_{3}{ }^{-}\right)$in drinking water became a global concern and efforts towards its removal mainly focused on addressing the source. Herein, we rationally designed a porphyrin-based covalent organic framework (PV-COF) with a cationic surface to provide electrostatic interactions and a porphyrin core to induce hydrogen bonding interactions for the efficient removal of $\mathrm{BrO}_{3}{ }^{-}$from water. Through $\mathrm{H}$-bonding and electrostatic interactions, PV-COF exhibited an exceptional bromate removal efficiency (maximum adsorption capacity, $Q_{\max }: 203.8 \mathrm{mg} \mathrm{g}^{-1}$ ) with the fastest uptake rate $\left(k_{\text {ads }}\right)$ of $191.45 \mathrm{~g} \mathrm{mg}^{-1} \mathrm{~min}^{-1}$. The bromate concentration was reduced to far below the allowed concentration in drinking water $(10 \mathrm{ppb})$ within 20 minutes. We studied the relationship between bromate adsorption and COF surface modification by metalation of the porphyrinic core or neutralization of the viologen linkers by chemical reduction. The bromate adsorption mechanism was studied by EDAX mapping and molecular simulations, and it was found that ion exchange and hydrogen bonding formation drive the adsorption. Importantly, PV-COF could be easily recycled several times without compromising its adsorption efficiency.
\end{abstract}

\section{Introduction}

Bromate $\left(\mathrm{BrO}_{3}{ }^{-}\right)$is a toxic substance responsible for the recall of large quantities of bottled drinking water in the US, Europe and across the Middle East. ${ }^{\mathbf{1 - 4}}$ It is formed in drinking water during the processes of ozonolysis and electrolysis of both fresh and seawater. ${ }^{5}$ On account of its serious toxic effects, which include central nervous system depression, haemolytic anemia, pulmonary edema, and even cancer, ${ }^{6}$ both the World Health Organization (WHO) and the Environmental Protection Agency (EPA) have set the maximum contaminant level of bromate in drinking water at $10 \mathrm{ppb}^{7}$ Ozone treatment is one of the most common methods used to disinfect drinking water and as

${ }^{a}$ Science Division, New York University Abu Dhabi, Saadiyat Island, Abu Dhabi, United Arab Emirates. E-mail: ali.trabolsi@nyu.edu

${ }^{b}$ Department of Chemistry, Khalifa University, P.O. Box: 127788, Abu Dhabi, United Arab Emirates

'The Materials Science Factory, Instituto de Ciencia de Materiales de Madrid-CSIC, 28049, Sor Juana Inés de la Cruz 3, Madrid, Spain

${ }^{d}$ Core Technology Platform, New York University Abu Dhabi, Saadiyat Island, Abu Dhabi, United Arab Emirates

${ }^{e}$ Membrane Biophysics and NMR, Institute of Chemistry, UMR 7177, University of Strasbourg, CNRS, Strasbourg, France

${ }^{f}$ School of Pharmaceutical Science and Technology, Tianjin University, 92 Weijin Rd., Nankai District, Tianjin, P. R. China

$\uparrow$ Electronic supplementary information (ESI) available. See DOI: 10.1039/c9sc04663a a result can lead to significant levels of bromate ingestion ranging from 120 to $180 \mu \mathrm{g}$ per day, much higher than is safely allowed. ${ }^{8}$ In consideration of the difficulties in removing bromate from water, efforts on reducing bromate levels of drinking water have mostly been limited to treating its source: by removal of its precursors $\left(\mathrm{Br}^{-}\right)$before ozonolysis and/or control of the ozonolysis process in order to minimize $\mathrm{BrO}_{3}{ }^{-}$ formation. Unfortunately, these processes require water treatment plants to make complex impractical adjustments in their day-to-day operations, and thus the water treatment industry is searching for accessible ways to remove bromate postozonolysis. This is an important but largely understudied area in drinking water research. ${ }^{9}$ Among the reported post-treatment methods (physico-chemical, electrochemical or light-triggered reduction, bio-reduction, and various forms of dialysis), ${ }^{\mathbf{1 0}}$ adsorption is the most scalable and cost-effective method whereby activated carbons ${ }^{\mathbf{1 1 - 1 3}}$ and inorganic substances ${ }^{\mathbf{6 , 1 4}}$ have predominantly been used as $\mathrm{BrO}_{3}{ }^{-}$sorbents. Yet, these materials suffer from low efficiency, limited and cost-ineffective regeneration ability, and slow kinetics. In contrast, organic polymers comprised of lightweight elements are known to have high water stability and excellent pollutant uptake capacities and can be easily regenerated, but have not been investigated as bromate sorbents.

Covalent organic frameworks (COFs) are a novel class of porous, crystalline materials with tunable structures and extensive surface areas. ${ }^{15,16}$ COFs have been utilized for the removal of 
various pollutants from water, including toxic dyes, ${ }^{17}$ heavy metals, ${ }^{18-20}$ pharmaceuticals, ${ }^{21}$ and other toxins. ${ }^{22}$ However, adsorption of $\mathrm{BrO}_{3}{ }^{-}$is unprecedented for COFs. Herein, we report a cationic porphyrin COF with viologen units (PV-COF) obtained through the Zincke reaction ${ }^{23}$ for the efficient removal of bromate from water. While a handful of porphyrin-based COFs have been reported, ${ }^{\mathbf{2 4 - 2 6}}$ they are synthesized through the formation of boronic esters or imine bonds, which are known to have limited chemical stability. Contradistinctively, PV-COF is formed from the generation of a quaternary ammonium salt, which does not easily hydrolyze. ${ }^{27}$ We tested the utility of PV-COF in removing bromate from drinking water because of its inherent properties, whereby its cationic charge can induce favorable electrostatic interactions with anionic $\mathrm{BrO}_{3}{ }^{-}$, and its porphyrin core can form hydrogen bonds ${ }^{28}$ with $\mathrm{BrO}_{3}{ }^{-}$. Bromate adsorption by PV-COF was extremely fast with a remarkable uptake rate constant of $191.45 \mathrm{~g}$ $\mathrm{mg}^{-1} \mathrm{~min}^{-1}$. At this rate, the reduction of an aqueous bromate concentration of $50 \mu \mathrm{g} \mathrm{L}^{-1}$ to less than $3 \mu \mathrm{g} \mathrm{L}^{-1}$, which is far below the allowed concentration in drinking water, occurred in just 20 minutes. The material exhibited a maximum uptake capacity $\left(Q_{\max }\right)$ of $203.8 \mathrm{mg} \mathrm{g}^{-1}$, which is one of the highest values reported to date. In addition, we post-synthetically modified PV-COF through metallation and chemical reduction, and tested the ability of products to adsorb $\mathrm{BrO}_{3}{ }^{-}$in order to understand the structure-property relationships which governed their performance.

\section{Results and discussion}

PV-COF was synthesized through the Zincke reaction between an amino-derivative of porphyrin (1) and the Zincke salt (2). In a typical experiment, 1 and 2 were reacted in a $1: 2$ molar ratio in a $4: 1$ mixture of ethanol : water under microwave irradiation at $90^{\circ} \mathrm{C}$ for 2 hours (Fig. 1). The crude solid was purified by extensive washing with ethanol and chloroform, and PV-COF was obtained in high yield (80 mg COF from $50 \mathrm{mg}$ starting porphyrin) as a powder insoluble in various solvents (water, ethanol, THF, chloroform, and DMSO). The Fourier transform infrared (FT-IR) spectrum of PV-COF showed signals corresponding to $-\mathrm{C}=\mathrm{N}-$ stretching at $\sim 1603 \mathrm{~cm}^{-1}$ and $1630 \mathrm{~cm}^{-1}$ belonging to the porphyrin and bipyridinium subunits, respectively (Fig. S1 $\dagger$ ). In addition, signals for $-\mathrm{N}-\mathrm{O}$ bond vibrations at 1340 and $1530 \mathrm{~cm}^{-1}$ that are present in the FT-IR spectrum of 2 are absent in the spectrum of PV-COF, which confirms the success of the Zincke reaction. Molecular-level characterization of PV-COF was further achieved using ${ }^{13} \mathrm{C}$ cross-polarization magic angle spinning (CP-MAS) solid state NMR (Fig. 2a), which exhibits a strong peak at $142.56 \mathrm{ppm}$ that corresponds to the pyridyl carbon atoms (Ar-C linker) and a peak at $128.39 \mathrm{ppm}$ that corresponds to phenyl carbons of the porphyrin subunit (Ar-C core). We also observed medium intensity peaks at 123.65 and $149.25 \mathrm{ppm}$ that correspond to the pyrrole rings of the porphyrin moiety. These findings confirmed the formation of the network structure as shown in Fig. 1.

Morphological studies on PV-COF using scanning electron microscopy (SEM) and transmission electron microscopy (TEM) revealed the presence of uniform spherical particles (Fig. 2b and c). Elemental mapping using energy dispersive spectroscopy (EDS) showed an even distribution of relevant elements (C, N and $\mathrm{Cl}$ ) throughout the spherical particles (Fig. S2 $\dagger$ ). An average diameter of $1.4 \mu \mathrm{m} \pm 0.18 \mu \mathrm{m}$ for these spheres was calculated from TEM micrographs (Fig. S3a $\dagger$ ).

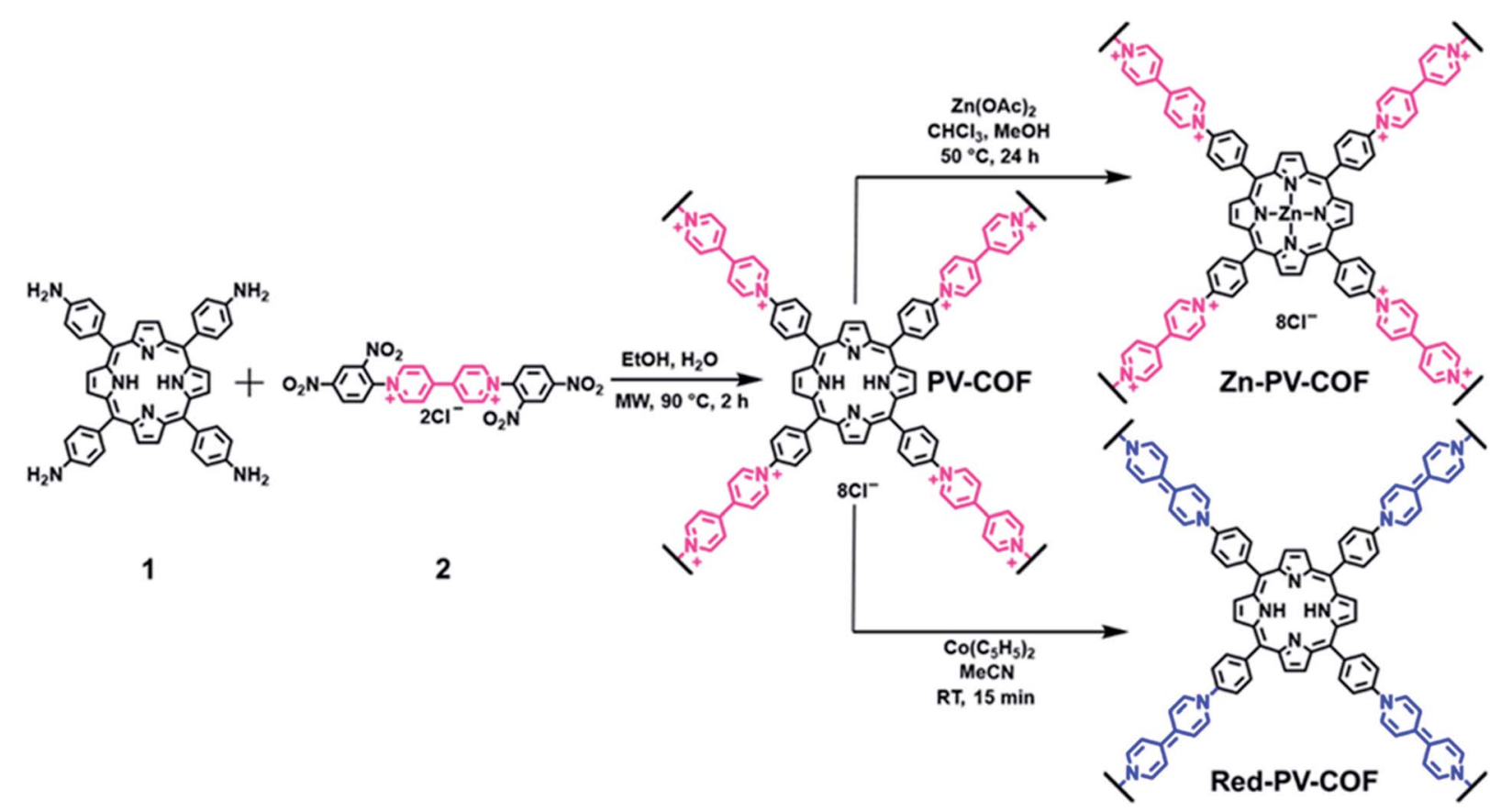

Fig. 1 Synthetic route to PV-COF through the Zincke reaction and its post-synthetic modifications by metalation of the porphyrin core (Zn-PVCOF)and chemical reduction of viologen units from a cationic to a neutral form (Red-PV-COF). 

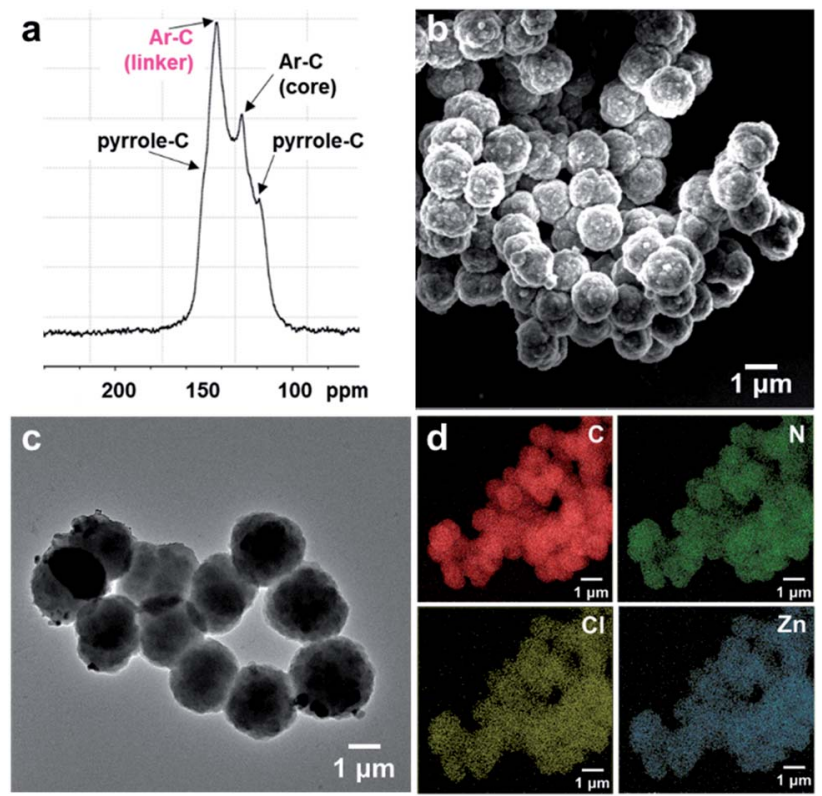

Fig. 2 (a) ${ }^{13} \mathrm{C}$ solid-state NMR spectrum of PV-COF with peaks assigned to relevant carbon atoms; (b) SEM image of PV-COF shows spherical particles with an average size of $1.4 \mu \mathrm{m}$; (c) TEM image of PVCOF; (d) elemental mapping of $\mathrm{Zn}-\mathrm{PV}-\mathrm{COF}$ showing an even distribution of constituent elements ( $C, N, C l$ and $\mathrm{Zn})$.

Similarly, dynamic light scattering measurements provided an average diameter of $1.8 \mu \mathrm{m} \pm 0.2 \mu \mathrm{m}$ with a polydispersity index of 0.206 (Fig. S3b†). The surface charge of the PV-COF particles was found to be positive ( $\zeta$-potential $=+13.6 \mathrm{mV}$ ) owing to the presence of viologen units in their backbone (Fig. S4†). The porosity of PV-COF was characterized by nitrogen gas sorption isotherm measurements. A modest Brunauer-Emmett-Teller (BET) surface area of $38.2 \mathrm{~m}^{2} \mathrm{~g}^{-1}$ (Fig. S5a $\dagger$ ) was calculated for the material, possibly due to the presence of chloride counterions that may block some of the network pores. The network was mesoporous in nature with a pore size of $2.3 \mathrm{~nm}$ (Fig. S5b†), which is in good agreement with the material's calculated pore size. Thermogravimetric analysis of PV-COF confirmed that $\sim 80 \%$ of the material remained stable up to $\sim 400{ }^{\circ} \mathrm{C}$ (Fig. S6 $\dagger$ ).

According to its powder X-ray diffraction (PXRD) pattern, $\mathbf{P V}$ COF is crystalline with Bragg diffraction peaks at $2 \theta=3.86^{\circ}$, $7.39^{\circ}$, and $10.90^{\circ}$. They were assigned to the (100), (200), and (300) Miller planes, respectively, in agreement with a tetragonal unit cell (Table S1†). Thus, a crystal model was built and geometrically optimized in the tetragonal $P \overline{4}$ space group, where PV-COF forms square layers that are disposed parallel to the $a b$ plane, with an optimized lattice parameter of $a=25.25 \AA$. In the fully eclipsed configuration, the PV-COF layers are $4.03 \AA$ apart along the $c$ axis, according to the optimized model and corresponding to the broad peak centered at $2 \theta=22.4^{\circ}$ in the experimental PXRD pattern. As shown in Fig. 3 , the simulated PXRD pattern of this model is in good agreement with the experimental data. Both the crystallinity and morphology were unaffected by acidic and basic pH (Fig. S7 and $\mathrm{S} 8 \uparrow$ ).

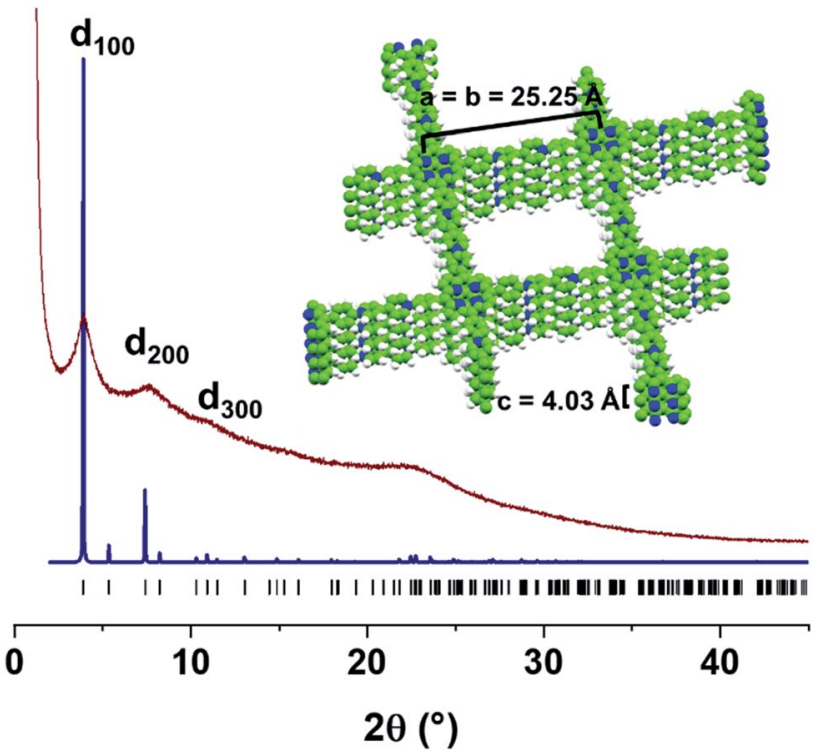

Fig. 3 Experimental PXRD pattern of the as-synthesized PV-COF (brown line) compared with the simulated pattern using the optimized crystal model (blue line), built in the $P 4$ unit cell with $a=b=25.25 \AA$, and $c=4.03 \AA$. Inset: space-filling view of stacked layers along $x$ and $y$ axes.

Porosity, hydrothermal stability, cationic surface, and the ability to form both electrostatic and hydrogen bonds with oxoanions encouraged us to investigate the $\mathrm{BrO}_{3}{ }^{-}$adsorption capability of PV-COF. To mimic practical conditions in a fullscale drinking water plant, the starting $\mathrm{BrO}_{3}{ }^{-}$concentration was set at $50 \mu \mathrm{g} \mathrm{L}^{-1} .{ }^{29}$ In a typical experiment, PV-COF (5 mg) was incubated with a $\mathrm{NaBrO}_{3}$ solution $(10 \mathrm{~mL})$ and $1 \mathrm{~mL}$ aliquots were removed at different time points $(1,2,5,10,15$, and $20 \mathrm{~min})$. These fractions were passed through a syringe filter $(0.2 \mu \mathrm{m}$ pore size $)$ and residual solutions were analyzed with an HPLC coupled to a triple quadrupole mass spectrometer (HPLC-QqQMS) to quantify the amount of $\mathrm{BrO}_{3}{ }^{-}$(details in the ESI $\dagger$ ). We found a remarkable decrease in the stock concentration of $\mathrm{BrO}_{3}{ }^{-}$to less than $3 \mu \mathrm{g} \mathrm{L} \mathrm{L}^{-1}$ within 20 minutes of PVCOF treatment, which corresponded to over $95 \%$ removal (Fig. 4a). The rate constant for the adsorption process was determined by fitting the data to a pseudo-second order kinetic model $^{30,31}$ and an adsorption rate of $191.45 \mathrm{~g} \mathrm{mg}^{-1} \mathrm{~min}^{-1}$ was calculated with a correlation coefficient of $\sim 1$, which is a value higher than that of any other reported adsorbent (Fig. 4b, c and Table S2 $\uparrow$ ). The maximum $\mathrm{BrO}_{3}{ }^{-}$absorption capacity of $\mathbf{P V}$-COF was estimated by an isotherm study using a range of bromate concentrations ( 12.5 to $200 \mathrm{mg} \mathrm{L}^{-1}$ ). We fitted the adsorption data to the Langmuir and Freundlich non-linear adsorption models, ${ }^{32,33}$ but a better fit was obtained with the former $\left(R^{2}=\right.$ 0.98 and 0.92 , respectively). A $Q_{\max }$ of $203.8 \mathrm{mg} \mathrm{g}^{-1}$ was calculated (Fig. $4 \mathrm{~d}$ and S9†), which is among the highest values reported to date for any class of $\mathrm{BrO}_{3}{ }^{-}$sorbents (Table S2 $\uparrow$ ). The mechanism of $\mathrm{BrO}_{3}{ }^{-}$adsorption involves exchange of counter ions. The relative amounts of $\mathrm{Cl}$ and $\mathrm{Br}$ change from $32.9 \%$ and $0.0 \%$, respectively, prior to adsorption (Fig. S2 $\uparrow$ ) to $4.6 \%$ and 

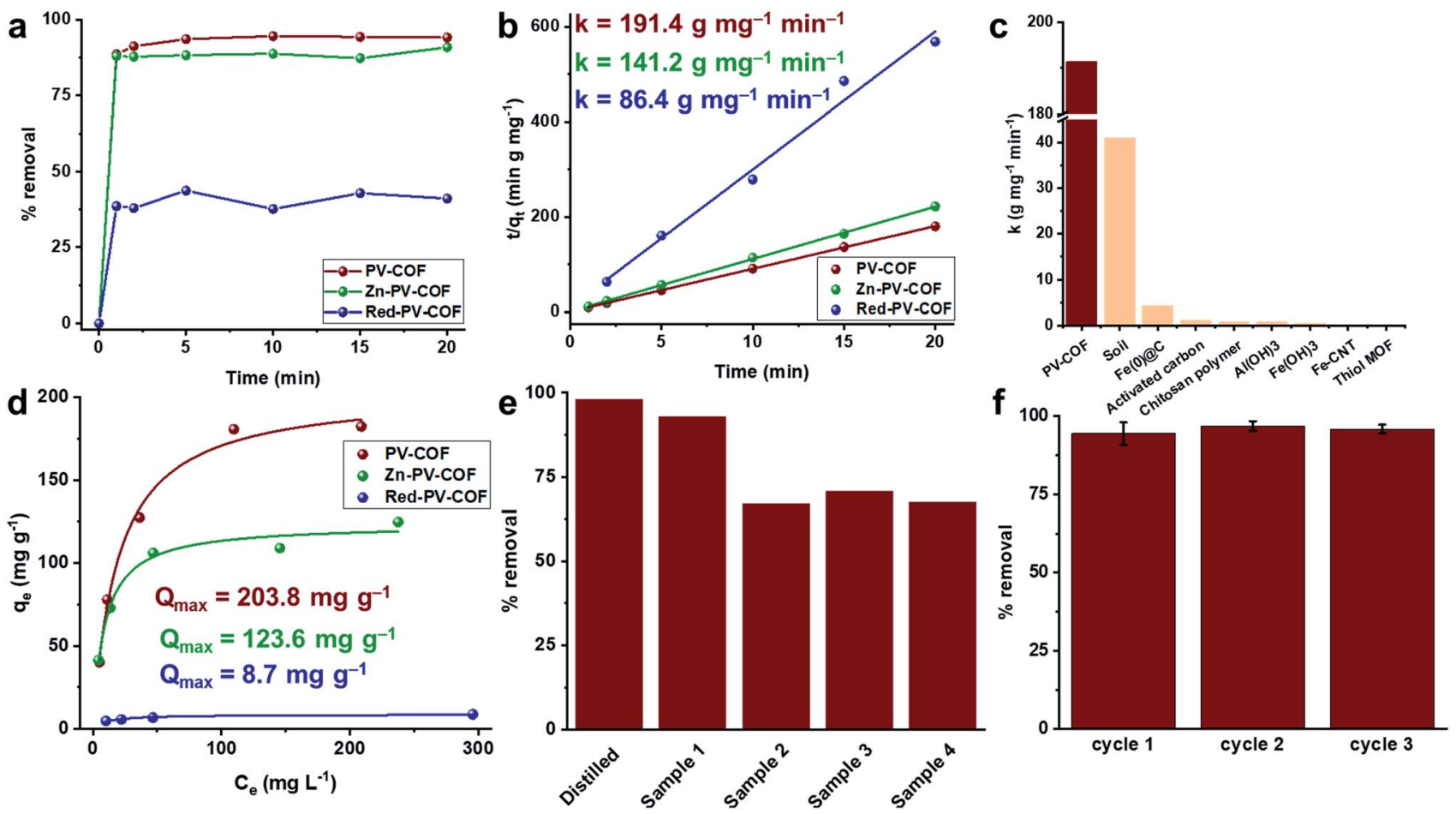

Fig. 4 Bromate adsorption results. (a) \% removal of $\mathrm{BrO}_{3}^{-}$by PV-COF, Zn-PV-COF and Red-PV-COF with $50 \mu \mathrm{L}^{-1}$ initial concentration of $\mathrm{BrO}_{3}{ }^{-}$at different time points $(n=3)$; (b) the pseudo-second-order kinetic plots for $\mathrm{BrO}_{3}{ }^{-}$adsorption by PV-COF, Zn-PV-COF and Red-PV-COF along with associated rate constants ( $k$ ); (c) a comparison of the rate constants of PV-COF and other reported bromate adsorbents; (d) Langmuir non-linear isotherm model fitting for PV-COF, Zn-PV-COF and Red-PV-COF along with determined maximum adsorption capacities $\left(Q_{\text {max }}\right)$ at $\mathrm{BrO}_{3}{ }^{-}$concentrations in the range $12.5-200 \mathrm{mg} \mathrm{L}^{-1}$; (e) \% removal of $\mathrm{BrO}_{3}{ }^{-1}$ after 20 min incubation of PV-COF with commercial water samples from the UAE, Italy and Norway to which $\mathrm{BrO}_{3}^{-1}$ was added at a concentration of $50 \mu \mathrm{g} \mathrm{L}^{-1}$. Water samples contained competitive anions, including bicarbonate $\left(0-182 \mathrm{mg} \mathrm{L}^{-1}\right)$, sulfate $\left(0-86 \mathrm{mg} \mathrm{L}^{-1}\right)$, chloride $\left(1.3-77 \mathrm{mg} \mathrm{L}^{-1}\right)$, nitrate $\left(0.3-1.1 \mathrm{mg} \mathrm{L}^{-1}\right)$ and fluoride $\left(0.1-0.5 \mathrm{mg} \mathrm{L}^{-1}\right)$; (f) regeneration efficiency of $\mathrm{PV}-\mathrm{COF}$ for $\mathrm{BrO}_{3}{ }^{-}$adsorption; uptake efficiency is preserved for at least three cycles.

18.8\%, respectively, post adsorption (Fig. S10 $\dagger$ ). This reduction in the relative amount of $\mathrm{Cl}$ and the increase in the amount of $\mathrm{Br}$ strongly suggest that $\mathrm{Cl}^{-}$counter ions are replaced by $\mathrm{BrO}_{3}{ }^{-}$. As a result of $\mathrm{BrO}_{3}{ }^{-}$adsorption, the total surface area of the material decreases to $30.0 \mathrm{~m}^{2} \mathrm{~g}^{-1}$ (Fig. S11 $\dagger$ ), the average particle diameter in solution increases to $2.2 \mu \mathrm{m}$ because of swelling and the average surface charge decreases to $+5.2 \mathrm{mV}$ as a result of surface-adsorbed $\mathrm{BrO}_{3}^{-}$(Fig. S12 $\dagger$ ).

To mimic the real-life conditions of adsorption, we performed experiments with commercial water samples to which $\mathrm{NaBrO}_{3}$ was added at $50 \mu \mathrm{g} \mathrm{L}^{-1}$. These samples contained other anions, typically in thousand times higher concentration ranges, including bicarbonate $\left(0-182 \mathrm{mg} \mathrm{\textrm {L } ^ { - 1 }}\right)$, sulfate $(0-$ $\left.86 \mathrm{mg} \mathrm{L}^{-1}\right)$, chloride $\left(1.3-77 \mathrm{mg} \mathrm{L}^{-1}\right)$, nitrate $\left(0.3-1.1 \mathrm{mg} \mathrm{L}^{-1}\right)$ and fluoride $\left(0.1-0.5 \mathrm{mg} \mathrm{L^{-1 }}\right)$. In spite of the presence of competitive anionic species at high concentrations, PV-COF removed up to $93 \%$ of $\mathrm{BrO}_{3}{ }^{-}$in 20 minutes (Fig. 4e). The effect of $\mathrm{pH}$ on the adsorption was also tested and it was found that an acidic $\mathrm{pH}$ of 5 does not alter \% removal in the first 20 minutes, but a basic pH of 8 decreases it to $\sim 70 \%$ (Fig. S13 $\dagger$ ). This can be explained by a partial loss of the cationic character of PV-COF: it is well known that bases reduce viologen units to radical cations, ${ }^{34}$ which have a lower affinity for bromate than dicationic viologens.
To evaluate the role that the network core units and surface modifications play in impacting $\mathrm{BrO}_{3}{ }^{-}$removal efficiency, we chemically modified the surface of PV-COF post-synthetically by: (1) metallating the porphyrin units with zinc metal ions (Zn-PV-COF, Fig. 1) which could potentially coordinate to bromate, or (2) chemically reducing the bipyridinium subunits using cobaltocene to neutralize the COF surface (Red-PV-COF, Fig. 1). Neither of the two modifications resulted in a change in the morphology as evidenced by SEM and TEM imaging (Fig. S14 and S15 $\dagger$ ). The average size of the particles remained the same for $\mathbf{Z n - P V - C O F}(\sim 1.4 \mu \mathrm{m})$, whereas there was a slight decrease in the size for Red-PV-COF $(\sim 1.2 \mu \mathrm{m})$, likely because of the loss of counterions (Fig. S16a and c $\dagger$ ). EDS mapping confirmed an even distribution of the transition metal as well as other constituent elements throughout Zn-PV-COF (Fig. 2d). The $\zeta$-potential of the metallated COF was measured to be $+25.2 \mathrm{mV}$ owing to the positively charged metal centers introduced (Fig. S16b $\dagger$ ). Conversely, the $\zeta$-potential for Red-PV-COF became negative and was measured to be $-24.1 \mathrm{mV}$ (Fig. S16d $\dagger$ ). FT-IR spectra of Zn-PV-COF and Red-PV-COF showed $-\mathrm{C}=\mathrm{N}$ - vibration signals from the porphyrin subunit at $1603 \mathrm{~cm}^{-1}$, but the latter lacked a signal at $1630 \mathrm{~cm}^{-1}$ due to the loss of $-\mathrm{C}=\mathrm{N}$ - bonds following reduction of the bipyridinium units (Fig. S17†). In addition, Zn-PV-COF exhibited a strong 
signal at $1001 \mathrm{~cm}^{-1}$, shifted from $966 \mathrm{~cm}^{-1}$ in PV-COF. This indicated an interaction of the $-\mathrm{C}-\mathrm{N}$ - bonds with the $\mathrm{Zn}$ metal center. Porosity and pore size distributions remained similar after metalation (Fig. S5c and $\mathrm{d} \dagger$ ), but reduction resulted in a significant increase in the surface area of Red-PV-COF to 306 $\mathrm{m}^{2} \mathrm{~g}^{-1}$ (Fig. S5e and $\mathrm{f} \dagger$ ). This can be explained by the removal of counter ions, which block some of the pores in PV-COF. Neither of chemical modifications imparted significant radical character to the material as evidenced by electron paramagnetic resonance (EPR) spectra (Fig. S18 $\dagger$ ). The PXRD pattern of Zn-PVCOF and Red-PV-COF showed a broadening of the peak corresponding to the (200) plane with increased intensity and a reduced intensity of the peak corresponding to the (100) plane (Fig. S19†).

Having fully characterized the modified materials, $\mathrm{BrO}_{3}{ }^{-}$ removal experiments were conducted as previously described. Adsorption rates were found to be $141.17 \mathrm{~g} \mathrm{mg}^{-1} \mathrm{~min}^{-1}$ and $86.43 \mathrm{~g} \mathrm{mg}^{-1} \mathrm{~min}^{-1}$ for Zn-PV-COF and Red-PV-COF, respectively (Fig. 4b). We hypothesized that the introduction of $\mathrm{Zn}$ atoms into the porphyrin cores may prevent the formation of hydrogen bonding between the core and $\mathrm{BrO}_{3}{ }^{-}$, which may effectively reduce the rate of adsorption. A molecular simulation of the interaction between $\mathrm{BrO}_{3}{ }^{-}$anions and the central porphyrin units indicated that the bromate anions might be forming $\mathrm{H}$-bonds with the central porphyrin core (Fig. S20 $\dagger$ ). On the other hand, when considering the periodic PV-COF structure, the results of simulation on the $\mathrm{BrO}_{3}{ }^{-}$sorption sites indicated that bromate anions are primarily adsorbed by forming $\mathrm{H}$-bonds with the hydrogen atoms of the porphyrin pyrrole groups that are pointing into the pores (Fig. S20 †). This was experimentally confirmed by FT-IR analysis, where the $-\mathrm{N}-$ $\mathrm{H}$ vibrations at $\sim 3100 \mathrm{~cm}^{-1}$ almost disappear post-bromate adsorption (Fig. S21 $\dagger$ ). Although $\mathrm{Zn}$ could serve as a coordination center for anions, it also increased the molecular weight of the material, so the net effect was a reduction in the $\mathrm{BrO}_{3}{ }^{-}$ adsorption rate. Similarly, neutralization of the bipyridinium subunit's cationic charge prevented the formation of electrostatic ion-paired interactions between the sorbent and $\mathrm{BrO}_{3}{ }^{-}$, the net effect of which reduced the adsorption rate even more dramatically. These results suggest that electrostatic interactions play a major role in the adsorption process. In terms of maximum uptake capacity for $\mathrm{BrO}_{3}{ }^{-}$, $\mathbf{Z n - P V - C O F}$ and Red-PVCOF do not perform as extraordinarily as PV-COF, but Zn-PVCOF nevertheless has one of the highest reported $Q_{\max }$ values at $123.60 \mathrm{mg} \mathrm{g}^{-1}$ (Fig. 4d).

Finally, we tested the regeneration ability of the bestperforming PV-COF. Adsorbed $\mathrm{BrO}_{3}{ }^{-}$could be desorbed by simple washing with a $40 \mathrm{mM}$ solution of $\mathrm{NaOH}$ followed by neutralization with $10 \mathrm{mM} \mathrm{HCl}$, as previously reported (details in the $\left.\mathrm{ESI}_{\dagger} \dagger\right)^{35}$ We tested our material for three consecutive cycles without significant loss of adsorption efficiency at both lower $\left(50 \mu \mathrm{g} \mathrm{L}^{-1}\right)$ and higher $\left(50 \mathrm{mg} \mathrm{L}^{-1}\right) \mathrm{BrO}_{3}{ }^{-}$concentrations (Fig. 4f and S22 $\dagger$ ). Furthermore, PV-COF preserved its morphology after the three cycles of adsorption (Fig. S23 $\dagger$ ). Additionally, no significant changes in the fingerprint region of the FT-IR spectrum of the material were observed (Fig. S24†), and crystalline nature was preserved (Fig. S25†). Because remediation of ground and drinking water typically involves packed-bed columns, ${ }^{36}$ we also conducted adsorption and regeneration experiments in the continuous flow setup (details in the ESI, Fig. S26 $\dagger$ ). The concentration of $\mathrm{BrO}_{3}{ }^{-}$was decreased from $50 \mu \mathrm{g} \mathrm{L}^{-1}$ to below the detection limit for three consecutive cycles of adsorption.

\section{Conclusions}

In conclusion, we designed and synthesized a novel porphyrinbased crystalline material, PV-COF, through the Zincke reaction, which proceeded in a very high yield. PV-COF exhibited a high efficiency for the adsorption of bromate, a carcinogen introduced into water during the process of ozonolysis. The rate of adsorption was measured to be $191.45 \mathrm{~g} \mathrm{mg}^{-1} \mathrm{~min}^{-1}$, which is one of the fastest rates reported to date, with a maximum uptake capacity value of $203.8 \mathrm{mg} \mathrm{g}^{-1}$. Chemical modifications to the structure of PV-COF, such as neutralization of its positive charge and introduction of a metal center, both reduced the uptake of $\mathrm{BrO}_{3}{ }^{-}$. These data indicated that electrostatic interactions and hydrogen bonding both contributed largely to the remarkable $\mathrm{BrO}_{3}{ }^{-}$uptake ability of this material. This is the first report on the use of COFs for the removal of toxic bromate from water, which will likely generate interest in the community for the continued design of COF-based materials for applications in environmental remediation.

\section{Conflicts of interest}

There are no conflicts to declare.

\section{Acknowledgements}

The research described here was sponsored by New York University Abu Dhabi (NYUAD), UAE. The authors thank NYUAD for its generous support of the research program at NYUAD. The research was carried out by using the Core Technology Platform resources at NYUAD. T. S. would like to acknowledge the Horizon Fellowship in Natural and Physical Sciences awarded by NYU GSAS. F. G. acknowledges the Spanish Ministry of Science, Innovation and Universities for funding through the "Ramón y Cajal" program. The authors are grateful to Christina Johnson for providing the graphic material.

\section{Notes and references}

1 F. Lawrence, Things get wrose with Coke, Guard, 2004,https:/www.theguardian.com/business/2004/mar/20/ medicineandhealth.lifeandhealth, accessed October 2019.

2 Muscat Dly, https://archive.muscatdaily.com/Archive/Oman/ High-level-of-bromate-found-in-bottled-water-in-Oman-

Ministry-orders-their-withdrawal-3yfb, 2015, accessed October 2019.

3 Arab News, 2017, https:/www.arabnews.com/node/1194726/ saudi-arabia, accessed October 2019.

4 C. Mercer, Beverage Dly, 2006, https:// www.beveragedaily.com/Article/2006/08/24/FDA-to-recall- 
more-bottled-water-in-bromate-scare, accessed October 2019.

5 Y. Jung, E. Hong, Y. Yoon, M. Kwon and J. W. Kang, Ozone: Sci. Eng., 2014, 36, 515-525.

6 A. Bhatnagar, Y. H. Choi, Y. J. Yoon, Y. Shin, B. H. Jeon and J. W. Kang, J. Hazard. Mater., 2009, 170, 134-140.

7 World Health Organization, Bromate in Drinking-water: Background document for development of WHO Guidelines for Drinking-water Quality, 2005.

8 M. J. McGuire, S. W. Krasner and J. T. Gramith, Comments on bromide levels in state project water and impacts on control of disinfectant by-products, Metrop. Walter Dist. South. Calif, Los Angeles, CA.

9 S. Hajizadeh, H. Kirsebom, I. Y. Galaev and B. Mattiasson, J. Sep. Sci., 2010, 33, 1752-1759.

10 A. J. Kedir and M. Vohra, Desalin. Water Treat., 2017, 80, 255267.

11 S. Hong, S. Deng, X. Yao, B. Wang, Y. Wang, J. Huang and G. Yu, J. Colloid Interface Sci., 2016, 467, 10-16.

12 C. Xu, X. Wang, X. Shi, S. Lin, L. Zhu and Y. Chen, Environ. Technol., 2014, 35, 984-992.

13 M. Siddiqui, W. Zhai, G. Amy and C. Mysore, Water Res., 1996, 30, 1651-1660.

14 S. Chen, L. Fang, Q. Zhu, L. Li and Z. Xing, RSC Adv., 2016, 6, 28257-28262.

15 A. P. Cote, A. I. Benin, N. W. Ockwig, M. O'keeffe, A. J. Matzger and O. M. Yaghi, Science, 2005, 310, 1166-1170.

16 P. J. Waller, F. Gándara and O. M. Yaghi, Acc. Chem. Res., 2015, 48, 3053-3063.

17 H. Fan, J. Gu, H. Meng, A. Knebel and J. Caro, Angew. Chem., Int. Ed., 2018, 57, 4083-4087.

18 S.-Y. Ding, M. Dong, Y.-W. Wang, Y.-T. Chen, H.-Z. Wang, C.-Y. Su and W. Wang, J. Am. Chem. Soc., 2016, 138, 30313037.

19 N. Huang, L. Zhai, H. Xu and D. Jiang, J. Am. Chem. Soc., 2017, 139, 2428-2434.
20 Q. Sun, B. Aguila, J. Perman, L. D. Earl, C. W. Abney, Y. Cheng, H. Wei, N. Nguyen, L. Wojtas and S. Ma, J. Am. Chem. Soc., 2017, 139, 2786-2793.

21 A. Mellah, S. P. S. Fernandes, R. Rodríguez, J. Otero, J. Paz, J. Cruces, D. D. Medina, H. Djamila, B. Espiña and L. M. Salonen, Chem. -Eur. J., 2018, 24, 10601-10605.

22 Y. Li, C.-X. Yang and X.-P. Yan, Chem. Commun., 2017, 53, 2511-2514.

23 T. Zincke, Justus Liebigs Ann. Chem., 1903, 329, 1-36.

24 X. Feng, L. Chen, Y. Dong and D. Jiang, Chem. Commun., 2011, 47, 1979-1981.

25 H. Liao, H. Wang, H. Ding, X. Meng, H. Xu, B. Wang, X. Ai and C. Wang, J. Mater. Chem. A, 2016, 4, 7416-7421.

26 G. Lin, H. Ding, R. Chen, Z. Peng, B. Wang and C. Wang, J. Am. Chem. Soc., 2017, 139, 8705-8709.

27 G. Das, T. Skorjanc, S. K. Sharma, F. Gándara, M. Lusi, D. S. Shankar Rao, S. Vimala, S. Krishna Prasad, J. Raya, D. S. Han, R. Jagannathan, J.-C. Olsen and A. Trabolsi, J. Am. Chem. Soc., 2017, 139, 9558-9565.

28 M. O. Senge, ECS Trans., 2015, 66, 1-10.

29 W. J. Huang and Y. L. Cheng, Sep. Purif. Technol., 2008, 59, 101-107.

30 Y.-S. Ho and G. McKay, Process Biochem., 1999, 34, 451-465. 31 T. Skorjanc, D. Shetty, S. K. Sharma, J. Raya, H. M. Traboulsi, D. S. Han, J. Lalla, R. Newlon, R. Jagannathan, S. Kirmizialtin, J.-C. Olsen and A. Trabolsi, Chem. -Eur. J., 2018, 24, 8648-8655.

32 D. Shetty, I. Jahovic, J. Raya, Z. Asfari, J.-C. Olsen and A. Trabolsi, ACS Appl. Mater. Interfaces, 2018, 10, 2976-2981.

33 D. Shetty, I. Jahovic, J. Raya, F. Ravaux, M. Jouiad, J.-C. Olsen and A. Trabolsi, J. Mater. Chem. A, 2017, 5, 62-66.

34 T. Škorjanc, D. Shetty, M. A. Olson and A. Trabolsi, ACS Appl. Mater. Interfaces, 2019, 11, 6705-6716.

35 J. Liu, W. Shi, Y. Liu, W. Ou-Yang and R. Zhao, Water Sci. Technol.: Water Supply, 2017, 17, 1062-1069.

36 D. M. Alzate-Sanchez, Y. Ling, C. Li, B. P. Frank, R. Bleher, D. H. Fairbrother, D. E. Helbling and W. R. Dichtel, ACS Appl. Mater. Interfaces, 2019, 11, 8089-8096. 